\title{
The Practice of Immigration Health in Complex Emergency Situations - A Case Study of Kosovo from March to July 1999
}

\author{
Brian D. Gushulak, D. W. MacPherson, H. Prochazka \& M. M. Cooper
}

\begin{abstract}
The need to rapidly transport refugees, displaced as a result of evolving complex humanitarian emergencies creates challenges for those refugee-receiving nations that require formal immigration medical screening of these populations. Balancing the need to expediently resettle the refugees with these legislative and regulatory medical requirements can be logistically and operationally difficult. During the 1999 Kosovo crisis, the Humanitarian Evacuation Programme from the Former Yugoslav Republic of Macedonia rapidly moved large numbers of Kosovar Albanian refugees to nations with existing formal immigration medical screening requirements. This paper describes the successful management and delivery of immigration health services during this complicated international event.
\end{abstract}

Dr. Brian Gushalak has been involved in migration health work since 1984 when he became a Canadian Immigration Medical Officer. Since then he has held a number of positions within the Canadian Health and Immigration Departments all dealing with aspects of health and mobile populations. In August of 1996 he was selected as the Medical Director of the International Organization for Migration in Geneva, a position he currently occupies.

Dr. M. Cooper. has worked for the Canadian Immigration Medical Service in the Philippines, Singapore and Canada. During the Kosovo Crisis she was stationed in Skopje, and assisted in the pre-departure medical management of individuals destined to Canada from $F Y R O M$ and Albania.

Dr. H. Prochazka is currentlystationed in England as the Regional Medical Officer for the Australian Department of Immigration and Multicultural Affairs. Dr. Prochazka has been active in the field of immigration health in situations of regular and emergency migration.

Dr. W. MacPherson, Dept. of Pathology and Molecular Medicine at McMaster University, has consulted to governments and agencies on matters related to mobile populations, including program development, health data management.

\section{Résumé}

La nécessité de transporter rapidement les réfugiés déplacés à cause d'urgences humanitaires complexes à évolution rapide représente un défi pourles nations receveuses de réfugiés requérant un tamisage médical routinier de sa population immigrante. Des points de vue logistique et opérationnel, il peut s'avérer fort difficile pour ces états de concilier la nécessité de relocaliser rapidement les réfugiés avec les exigences de leurs lois et règlements en matière médicale et sanitaire. Lors de la crise du Kosovo de 1999, le Programme d'Évacuation Humanitaire del'ancienne république yougoslave de Macédoine déplaça rapidement un grand nombre de réfugiés albanais kosovars vers des nations requérant formellement un tamisage médical de sa population immigrante. Cet article décrit la gestion et la distribution réussies de services de santé à l'immigration au cours de cet événement international complexe.

\section{Introduction}

Complex humanitarian emergencies (CHEs) are characterized by environmental disasters or severe social-political disruptions, which affect the ability of a population to provide the basic necessities of life: food, water, shelter, and physical security. Very often, CHEs are associated with dramatic and unstable conditions, which make prediction of the magnitude and direction of needs for the affected population very difficult. In addition, mass movement of populations may also be a characteristic of CHEs. The dynamic conditions associated with CHEs pose formidable challenges for national and international acute response teams and relief agencies who are responsible for delivering services to affected populations.
During the initial phases of CHEs, many of theimmediateinterventions are focused on the provision of essential services to vulnerable populations. These services involve the provision and support of shelter, nutrition, sanitation and disease control. Health protection provisions and medical care are essential components in the management of complex emergencies.

When the displaced or affected populations are managed locally or within the region of the disruption, health service delivery remains centered on the provision of humanitarian care to those inneed, and the prevention of communicable disease outbreaks. However, if the emergency evolves to the point where it becomes necessary to transport the affected population across international borders, additional medical issues involving international, frontier and quarantine health must be considered.

These international and quarantine health activities deal with the medical and regulatory interventions related to immigration and refugee resettlement that are required or recommended by some of the nations that receive or harbor migrant populations. The delivery of these mandatory immigration health practices in CHEs can be extremely challenging. Much of that challenge results from the fact that the practice of immigration health is based on regulated, regimented systems of organized border control requirements whileCHEs take place in rapidly evolving, dynamic environments, often marked by poorly controlled environmental, civil or social situations. When these events are associated with the international movement of the affected 
populations, the international implications of existing quarantine legislation and the containment of diseases of international health importance must be considered. At the same time, undue effort in this regard must not delay or interfere with the provision or delivery of necessary humanitarian or medical assistance.

The 1999 situation in the Southern Balkans was a $\mathrm{CHE}$ during which the international community was faced with managing a refugee population from both a regional and international perspective. Many of the exigencies related to formal immigration health requirements had to be dealt with in a manner that was both expedient and responsive to the changing social and political circumstances in the region. Developing the programmes for immigration health, and delivering those programmes while considering the health of the refugees as well as the national requirements of those countries that received the refugees, was accomplished without significant complication.

This article reviews the immigrationrelated aspects of health management associated with the population of refugees who were evacuated internationally during the Kosovo crisis of spring and summer 1999. The article describes the approaches developed to deal with some of the acute medical needs of the affected population, the humanitarian consideration to ensure fitness to be transported, and the need to be in compliance with the legislative requirements of some receiving host nations. Australia, Canada and the United States of America are specific destination and host countries where immigration and public health legislation governing the admission of refugees was considered during the Kosovo crisis. The model programmes of health assessment for mobile refugee populations undergoing humanitarian evacuation to these countries will be described.

Since its inception in 1951, the International Organization for Migration (IOM), an intergovernmental, humanitarian organization, has acted with its partners in the international commu- nity in events such as the Kosovo crisis to assist in meeting the operational challenges of migration. During the crisis in the Southeast Balkans, IOM was responsible for the majority of air transport for refugees being resettled or evacuated from the region to international sites. In 1999, IOM provided direct air transport assistance to 59,993 individuals evacuated from the Former Yugoslav Republic of Macedonia (FYROM) under the Humanitarian Evacuation Programme (HEP) managed by the United Nations High Commissioner for Refugees (UNHCR) ${ }^{1}$.

During the past twenty years, IOM Medical Services has provided direct immigration health and travel services to over 1.5 million migrants moving to new international destinations. In providing transportation assistance to migrants, IOM has been active in supporting the health of those individuals. During the provision of those services, IOM has acquired extensive experience in managing the legislative and regulatory health requirements associated with migration. IOMMedical Services has provided technical immigration medical services for Australia, Canada, the United States and other nations for more than 30 years. Basic migration and transport health services for the majority of individuals evacuated by air from FYROM under the HEP were provided by IOM.

\section{The History of the International Movement of Refugees Resulting from the Kosovo Crisis}

The humanitarian crisis that followed the commencement of NATO military operations on March $24^{\text {th }}, 1999$, was the product of a long-standing deteriorating civil situation in Kosovo. During that period of civil instability, before the beginning of NATO air operations, UNHCR estimated that more than 400,000 peoplehad been forced to leave their homes. In this time before commencement of the NATO air strikes some 230,000 people were displaced within the borders of Kosovo itself while others fled to other countries, primarily in Europe.
The beginning of military activity on March $24^{\text {th }}$ was immediately followed by the widespread forced migration of the majority of the ethnic Albanian population living in the Kosovo province of Yugoslavia. UNHCR estimated that 230,000 Albanian Kosovars had been expelled from Kosovo by April $2^{\text {nd }}$. Displaced populations of this magnitude had not been seen in Europe since the end of the Bosnia conflict in the mid1990s. The volume and rate of the displacement was dramatic, with up to 40,000 individuals arriving in FYROM within a single 24 -hour period.

In the 10 days following the commencement of hostilities nearly 120,000 Kosovo refugees had arrived in Albania, 70,000 in FYROM, 30,000 in Montenegro and 7,500 in Bosnia and Herzegovina. Depending on location, the displaced individuals were housed with local host families, in community structures such as schools or factory buildings, or in refugee camps constructed to deal with the population flow. By April $4^{\text {th }}$ the situation in FYROM had reached the point where UNHCR recommended the beginning of international evacuation of some of the refugees to ease the burden on the humanitarian operations. The initial resettlement was intended to manage the refugees within the immediate region and within Europe, as geographically close to Kosovo as possible. However, by the $30^{\text {th }}$ of April the burden of the human crisis had reached a level where UNHCR made a formal request thatnon-European nations begin operations to evacuate Kosovo refugees from camps in FYROM.

The humanitarian evacuation operations were required "to preserve the stability of the FYR of Macedonia" ${ }^{2}$ and were initiated by a letter from Madame S. Ogata, the High Commissioner of UNHCR, to the governments of Australia, Canada and the United States. Specifically, these nations were asked to undertake planned evacuations from the refugee camps in the Skopje area. UNHCR had indicated that the longdistance evacuations, a process which had been deferred during the initial phase of the crisis in a desire to maintain the displaced refugees as close to their

Refuge, Vol. 18, No. 5 (January 2000) 
homes as possible, were now necessary as the numbers of refugees in FYROM approached 170,000 . This number of refugees was felt to exceed the physical, economic and political capabilities of the region to provide the humanitarian care required. Following the UNHCR request, Australia agreed to accept 4,000 refugees, Canada 5,000 and the United States 20,000.

\section{The Health/Medical Assessment of Refugees}

Three independent processes were involved in the health and medical assessments of the refugees in FYROM:

1. An initial health assessment to deal with acute or pre-existing medical conditions,

2. A "fitness to fly" assessment of individuals identified for international humanitarian evacuation, and

3. Routine immigration medical requirements as determined by the receiving nations.

Prior to initiating the second and third health assessments, individuals had to be identified as being willing to undergo international humanitarian evacuation on a voluntary basis.

\section{Case Selection for International Humanitarian Evacuation}

Refugees arriving overland to the FYROMwere received and registered in a joint UNHCR/IOM database. Those registered included refugees housed in camp situations and others who found shelter in the community. From the nearly two hundred thousand refugees in FYROM, UNHCR identified individuals and family groups for whom international resettlement was a priority. The criteria for priority determination were:

1. Single parent families,

2. Unaccompanied minor children,

3. Elderly, and

4. Those with serious medical conditions requiring urgent medical or surgical intervention.

These criteria were established by $\mathrm{UNHCR}$, and they assisted in the identification of vulnerable groups within the refugee population, who were in the greatest need of protection. In all cases, humanitarian evacuation was a voluntary process with families and individuals expressing a desire to leave the local situation in FYROM.

The presence of family members at the international destination, a factor which made reception and accommodation easier, and the maintenance of the family unit, were two additional issues considered in the process of selection for international humanitarian evacuation.

Information on those individuals who were identified under these criteria was offered to representatives of nations that had offered to receive refugees from FYROM. During the Kosovo crisis, UNHCR had received offers of placement for over 130,000 refugees. In the case of Australian, Canadian, or United States destined refugees, national immigration and refugee agencies and departments selected individuals for resettlement. Once the receiving nation had agreed to receive the refugees, the travel and immigration related health assessment of the refugees began. That process, while slightly different for each of the threecountries, involved the same basic and contiguous, but conceptually separate, medical evaluations that were related to the specific stages of the ultimatejourney.

The challenge facing immigration officials was the need to manage immigration medical requirements in the face of a rapidly evolving crisis and the humanitarian imperative to move several thousands individuals over a short period of time. The initial approach developed by nations with mandatory immigration health requirements involved the transport of individuals to transit centers in the country of destination. Upon arrival, detailed immigration medical examinations for the refugees were conducted. While this rapid phase of the evacuation was underway, processes were put in place to quickly complete formal immigration medical screening in FYROM.

Completing the immigrationmedical examination prior to the departure of refugee populations has both positive and negative attributes. Refugees who have completed their immigration medical formalities can be introduced directly into the general population. Consequently, the need to house or detain the refugees in processing centres, which often tend to be military establishments, is eliminated. Reducing the time spent by families in these controlled and supervised environments may facilitate the introduction to the regular aspects of the new society. Conversely, regular, controlled access to refugee populations housed in controlled environments, such as military installations, after arrival in the hostnation, can facilitate the recognition and management of health and medical conditions that may not be adequately assessed during the traditional immigration medicalexamination.

Developing the ability to perform complete immigration medical screening services in FYROM allowed the receiving nations the option of having the medical screening performed prior to departure or on arrival.

\section{General Medical Assessment}

On arrival in FYROM, refugees from Kosovo who required medical assistance or care received their services from health agencies or organizations working under the umbrella of UNHCR. Depending upon whether the refugees were accommodated in camps or in the community, health care was provided at camp clinics or hospitals by medical nongovernmental organizations or by local health providers in FYROM.

\section{Fitness to Fly Assessment}

Independent of the immigration medical requirements of the resettlement nations, the health of the refugee populations selected for international evacuation had to be considered in terms of the journey itself. As the main provider of air transport for the HEP from FYROM, IOM was responsible for thephysicalmovement of those selected for resettlement.

The medical evaluation of refugees selected for international resettlement included an evaluation of the individual's health condition and the fitness to 
fly to the destination. For all transport activities, IOM routinely considers the health of migrant passengers in terms of the potential adverse impact of the air and associated ground journey. Medical escorts are provided in situations where ill or disabled migrants are required to travel long distances and where assistance may be required during the flight.

Managing the medical and immigration health aspects of air travel during the initial phase of the HEP from FYROMwas logistically difficult. Much of that difficulty resulted from the fact that the movements had to be undertaken within constraints of time and limited access to some medical facilities and services.

For those refugees for whom a detailed medical evaluation was deferred until arrival at the destination, a limited pre-flight evaluation was undertaken. Local, culturally and linguistically appropriate physicians obtained a basic medicalhistory and performed a simple visual inspection. Depending upon the individual history and clinical status of the refugee, more detailed evaluation including vital signs, auscultation and the provision of medications was undertaken. Those refugees deemed fit to fly were then classified into three main categories:

1. Those with no obvious medical problems.

2. Those with pre-existing medical conditions that would require routine follow up in the future, and

3. Those with pre-existing medical conditions that required expedient attention on arrival.

To facilitate the rapid triage of the arriving refugees and to compensate for linguistic difficulties related to limited access to translators on arrival, each of the three groups of departing refugees, as defined above, was provided with a color coded card that indicated the results of the preflight medical assessment. These cards were positioned to readily identify the individual on arrival, and to permit a rapid visual triage to the appropriate level of medical care. To assist triage and detailed medical examination at the receiving destina- tion, each refugee also carried a form noting the presence of health conditions and illnesses identified during the preflight evaluation. Specific questions (cough, hemoptysis, and fever) regarding symptoms of active tuberculosis were asked of the refugees. Individuals with positive responses were referred for more detailed assessment. No cases of suspect tuberculosis were boarded.

\section{Immigration Screening}

\section{Routine Immigration Medical Requirements of Receiving Nations}

Nations who have long-standing immigration programmes also have regulatory and legislative procedures for the medical evaluation and screening of refugees and asylum seekers. These procedures are often, although not necessarily exclusively, related to national quarantine practices and protection of the public health. The immigration medical examination for refugee populations is generally undertaken to identify conditions and illnesses of public health importance that may affect either the refugee population or the localpopulations, which receive the refugees. Traditional foci of interest in this regard have been communicable infectious diseases such as pulmonary tuberculosis and sexually transmitted diseases, as well as some psychiatric disorders. Immigration medical screening and assessment may be undertaken either before arrival at the resettlement destination or after arrival.

The post-arrival assessment is practiced in situations where refugee claimants or asylum seekers present at frontier or border locations or alternatively request formal protection following entry to a country as a visitor, student, labor migrant or on arrival by some other irregular means. Depending upon the national legislation, individuals are often directed to specific clinics or practitioners for medical assessment, follow up investigation, treatment or preventive therapy, according to national standards ${ }^{3}$.
The other major method of undertaking immigration medical screening of refugees is to perform the process prior to the refugee travelling to the receiving host country. Pre-departure immigration medical evaluation has been the traditional approach practiced by the nations who accept the majority of internationally recognized refugees for permanent resettlement. In this group of nations Australia, Canada and the United States require that identified refugee populations complete immigration health formalities prior to departure to the receiving country.

Once the decision had been made to endorse the long-distance resettlement of refugees from FYROM, those nations receiving refugees began to balance the need to move the individuals in a humane, but expedited manner, while still satisfying their national immigration medical requirements. As noted above, the Kosovo-related refugee crisis in FYROM created a situation in which both of the approaches (pre-departure and post-arrival assessments) were utilized under less than optimum circumstances.

\section{Pre-Departure Immigration}

\section{Assessment}

During the course of the Kosovo crisis, some nations established procedures that allowed for the normalised immigration medical assessment of groups of refugees selected for resettlement. In certain situations, the United States and Canada arranged for the completion of formal immigration medical evaluation of selected refugees prior to departure. The Canadian Government also established an additional selection stream for refugees with family members already in Canada, separate from the 5,000 refugees accepted through the UNHCR-requested HEP. Individuals in these cohorts completed full immigration medical formalities prior to resettlement, in common with other refugee operations in other areas of the world. Having completed legally required medical investigations, these groups of refugees were allowed to immediately proceed into the local envi- 
ronment on arrival and did not require passage through transit facilities.

\section{Post-Arrival Immigration Assessment}

For those refugees who were evacuated internationally without having completed full immigration medical investigation, the required medical assessments and follow up were undertaken in transit facilities at the destination. A single location in the United States (Fort Dix, New Jersey), two sites in Canada (Trenton, Ontario and Greenwood, Nova Scotia) and a single site in Australia(Sydney) were used to perform the immigration medical screening assessments.

Following the completion of the postarrival medical screening and other immigration formalities, refugees were introduced into the local community. The duration of time between arrival and dispersion into the local community varied between reception nations. In some of these situations completion of formalities, determination of appropriate destinations and transfer to the community took several weeks.

\section{Outcomes of Systems Put in Place to Effect Immigration Medical Assessments}

\section{The Process for Canada}

Humanitarian evacuation cases for Canadian destinations were assessed under the IOM fitness-to-fly protocol (colour-coded IOM cards to indicate medical conditions) immediately prior to embarkation. Refugees were allowed to proceed if they were determined able to complete the flight without serious in-flight medical events and were in possession of adequate medication for pre-existing medical conditions for the duration of the journey. Of the more than 5,000 individuals assessed for HEP to go to Canada, only 4 were found to be unfit to travel for medical reasons. Of those, two wereelderly females with severe lung disease, while the remaining cases involved poorly managed psychiatric conditions.
Refugees were transported to Canadian Military installations in Trenton, Ontario and Greenwood, Nova Scotia. At these locations the refugees were triaged on the basis of the pre-departure medical assessment and colour-coded card classification. Those with red cards (in need of expedient medical assessment) were often transferred tolocal hospitals for more complete evaluation and treatment where required.

Medical screening on arrival in Canada included a chest $X$-ray, and serologic assessment for syphilis and hepatitis $B$. These investigations, carried out soon after arrival, were completed to satisfy immigration medical requirements related to infectious diseases of public health importance. A medical examination and a health history were also obtained before the refugees were dispersed to host communities throughout Canada.

\section{The Process for the United States}

During the initial phase of the HEP, Kosovar refugees destined for the United States received the "fitness to fly", predeparture examination and colour-coded card categorisation as described above. They then entered the United States through McGuire Air Force Base, where they were temporarily housed atFt. Dix Base. At that installation, the refugees completed the required immigration assessment formalities and other processes for resettlement in US communities.

Later in the course of events it became possible to perform complete US immigration medical evaluation in Skopje and those refugees departing for the US after that time had their health assessment performed by IOM in FYROM. Routine US immigration medical examination includes the following:

1. detailed history and physical examination.

2. chest radiograph for those older than 15 years of age.

3. serological test for HIV for those older than 15 , and

4. serological test for syphilis for those older than 15.

Immigrants destined to the United States received at least a single dose of routine vaccinations, according to US standards. Refugees were referred for immunization and vaccination on arrival in the United States. ${ }^{4}$

\section{The Process for Australia}

Refugees destined for Australia were faced with the longest travel distances of any of the populations relocated during the crisis. Flights for Australia departed from either Thessaloniki, Greece or Rome, Italy, necessitating considerable time and some transport even before the final flight began. It was not unusual for refugees travelling from FYROM to Australia to spend in excess of 36 hours travel time.

To reduce the risk of in-flight medical events Australian immigration medical officers established a three layered medical assessment process. Refugees accepted for evacuation to Australia initially received a preliminary medical examination performed by an Australian medical officer. Immediately prior to departure, pre-embarkation medical screening was undertaken. Finally, on arrival in Australia, the refugees underwent a more detailed medical examination, which included radiological examination for pulmonary tuberculosis.

\section{Balances Between Rapid Integration vs. Camp Life at Destination}

At the time of the writing of this article, evaluations of some of the details relating to the operations and outcome of the processes described above have only begun tobe reported. ${ }^{5}$ Some general observations, however, are possible.

The fitness to travel pre-departure screening process was effective. For some 41,000 individuals transported by IOM for whom pre-departure fitness to fly assessments were undertaken, only one serious in-flight medical event occurred. The single fatality was an acute cardiovascular death in an individual with identified underlying illnesses who was travelling with medical escort. Several individuals with unstable conditions, such as angina pectoris, severe fever of unknown origin, impending la- 
bour and delivery and acute psychiatric conditions, were temporarily deferred to allow for treatment. During the course of the programme, less than 10 individuals were permanently unable to travel by air.

Prolonged contact with government medical personnel was available for those refugees who were housed in processing centres after arrival. This sustained health care provider contact and follow up allowed for more enhanced recognition and quantification of health care issues than was provided by routine immigration medical screening. ${ }^{6}$ This was particularly true in the quantification of pharmaceutical and medication use and the recognition of some mental health conditions. Longer term health and integration outcomes between cohorts of refugees housed for extended periods of timemilitary or controlled environments pending medical screening, compared with those screened overseas and introduced directly into the community, are currently undefined.

\section{Issues That Could Be Examined In Greater Detail Over The Near Future Will Include the Following}

1. Whether post-arrival screening in transit areas, procedures that were used for those refugees who had not completed immigration medical formalities prior to departure, affected the intent or desire of the refugees to return to Kosovo following the cessation of hostilities.

2. The cost of providing immigration medical procedures at the point of origin as opposed to following arrival.

3 . The degree and nature of differences in the health, mortality and morbidity of populations who had their medical screening before departure as compared to those examined on arrival.

4. The differences in the health, mortality and morbidity of populations who were rapidly integrated into the community compared with those who stayed in camps in the host country before integration.

\section{Conclusions}

The 1999 Kosovo crisis and the associated Humanitarian Evacuation Programme from FYROM created several logistical and operational challenges to those refugee-receiving nations that require formal immigration medical screening. Meeting those challenges in the midst of a complex humanitarian event was accomplished in a flexible manner with the assistance of international organizations, national public health and immigration health officials.

The development of standardised approaches allowed for the rapid movement of selected refugee populations within the technical and legislative requirements of national screeningguidelines.

The effectiveness and long term impact of required medical screening completed prior to departure, as compared to screening on arrival in these situations should be evaluated in detail.

As noted above detailed studies are underway, but from preliminary reports it appears that secretion positive tuberculosis in the transported population was in the range of $50-60$ cases per 100,000 . Total active cases of tuberculosis (smear positive and smear negative) was in the range of $175-200$ cases per $100,000 .^{7}$ Hepatitis serology in Kosovar refugee populations examined in Italy in 1999 suggest that exposure to hepatitis A was universal in this population by the second decade of life and that the prevalence of hepatitis B surface antigen $(\mathrm{HbsAg})$ was approximately $3.0 \%$ in those tested. ${ }^{8}$

\section{Acknowledgments}

The authors would to acknowledge the assistance and activities of Dr. Tom O'Rourke, Dr. Niels Moller, Dr. Brenda Cholin and theentire IOMMedical Services team operating in Skopje, FYROM.

\section{References}

1. IOM. Movement Statistical Reporting System. August 1999, Geneva.

2. UNHCR Press Release. Ogata Says Situation Deteriorating in Kosovo, Urges Action to Avert Disaster. March 11, 1999. Geneva.
3. Helbling, P. (Border health examination). Schweiz Rundsch Med Prax 1997;86:794796.

4. Public Health Services Technical Instructions for Medical Examination of Aliens. CDC 1992

5. Yesky, K. Health Status of and Intervention for U.S.- Bound Kosovar Refugees - Fort Dix, New Jersey, May-June 1999. MMWR. 1999;48:729-732.

6. Cookson, S. Division of Quarantine, CDC Atlanta, personal communication.

7. Cookson, S. Divison of Quarantine, CDC Atlanta. St John. Lab Center for Disease Control, Health Canada, Ottawa.

8. Germinario, C., M. Chironna, P.L. Lopalco, and M.Quarto. Prevention and Control of Viral Hepatitis in Migrants and Refugees. Viral Hepatitis Prevention Board Symposium. Venice, Italy. September 1999. a

\section{Somali Refugees} in Toronto:

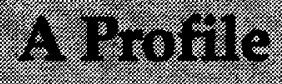

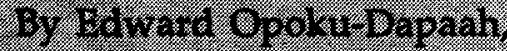 1905 \\ $18 B N .1-50014 \cdot 278 \times x: 130$

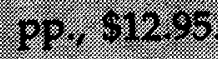

Thit. is the Rist comprehen.

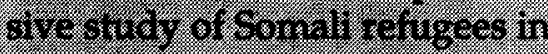

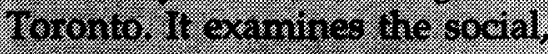

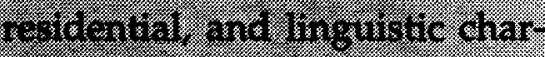

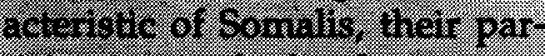

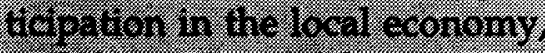

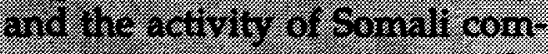

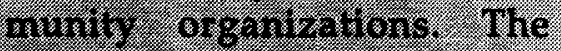

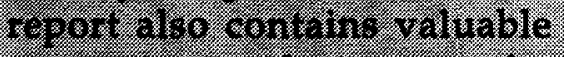

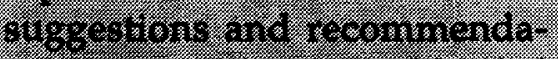

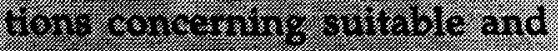

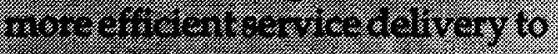

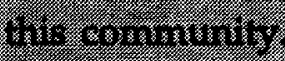




\author{
Refuge \\ Centre for Refugee Studies \\ Suite 322, York Lanes \\ York University \\ 4700 Keele Street, Toronto \\ Ontario, Canada, M3J 1P3 \\ Phone: (416) 736-5663 \\ Fax: (416) 736-5837 \\ Email: refuge@yorku.ca
}

\title{
Summer Course on Refugee Issues
}

\section{Toronto, June $11=18,2000$}

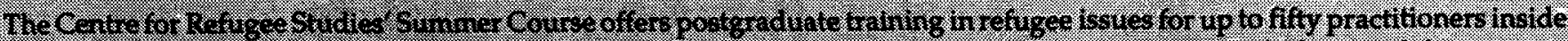

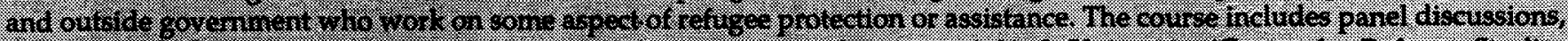

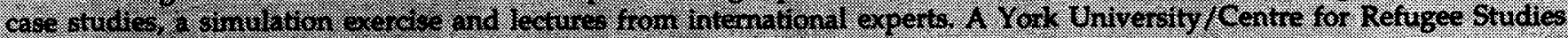

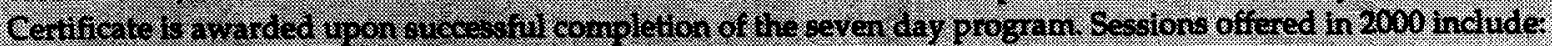

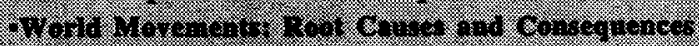

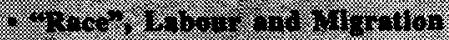

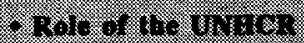

- 3 .

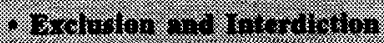

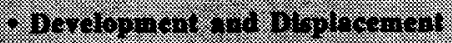

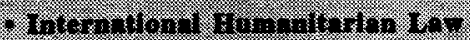

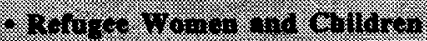

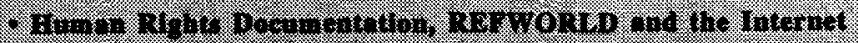

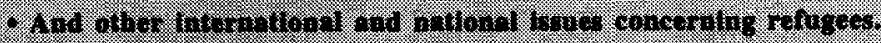

Counge Ree: 5750 Late regibtration after Warch 31, 2000, 5850

Fees arein Canadiandollarsand Indude materbls. Food and accommodation are extra. Reasonably priced accommodation ard to od areavallable or camplus. Partialsubsidies areavallable forlow-income participants. Alimited number of intensiups, including full cortuse subsidy, are avallable for York University students. Deadline for subsidy and internstip applications is Fobrandy 1,2060.

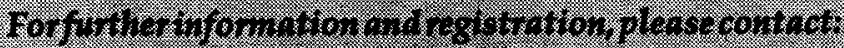

\section{Sharryn Aiken, Academic Director}

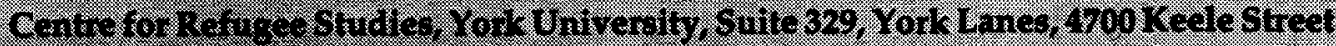

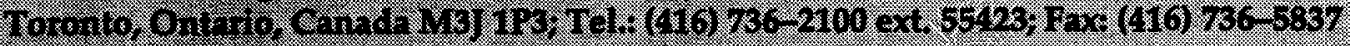

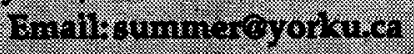

